\title{
The research of reverse logistics in coal mine
}

\author{
Guo Naidi, a, Mao Jia ${ }^{1, b}$ and Zhang Xiuzhi, ${ }^{2, c}$ \\ ${ }^{1}$ College of Transportation, Jilin University, Changchun, China \\ ${ }^{2}$ Institute of Mechanical Science and Engineering, Jilin University, Changchun, China

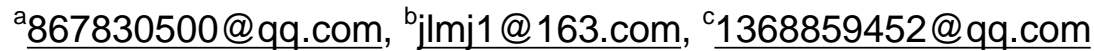

\begin{abstract}
Keywords: Reverse Logistics; Coal Mine Enterprise; Operation Method.
Abstract. Reverse logistics is a relatively new field in logistics research and has always been enjoy the reputation of environmental logistics. Coal production not only has relatively large pollution for the environment and serious waste,but also there are plenty of recyclable materials. The introduction of reverse logistics in coal mine logistics management, not only can save the cost of enterprises, but also can reduce the pollution of the environment. According to the practice of coal mine, this paper makes a preliminary discussion on the meaning, characteristics and content of coal mine reverse logistics and gives the preliminary conclusions, which practices in reverse logistics of coal mine.
\end{abstract}

\section{Introduction}

Coal is a major component of primary energy in our country. There is a great variety of materials consumed by coal production, which is an important part of the coal production cost. There is a big difference between the coal mine enterprise logistics and the generally studied manufacturing industries that the reverse logistics has extremely important significance to its logistics management. Due to the material consumed in the production process of coal mines does not constitute the final product, the material management of the coal mines is concentrated in the enterprises, which has the advantages that the general industry does not have for material management. Coupled with the dynamic nature of coal production sites, determined the frequent changes of the material use points, which makes a variety of materials recycling reuse become a norm of business logistics management. Coal mine has a long history of "repairing the old and reusing the waste" that consciously practice in the enterprise, which itself illustrates the importance of reverse logistics to the coal business. Although the traditional management of "repairing the old and reusing the waste" lacks of systematic theoretical guidance that still achieves considerable benefits is the solid foundation for further systematic reverse logistics management.

\section{The concept of reverse logistics and the significance to coal mines}

At present, many scholars have defined the reverse logistics, which can generalize its characteristics roundly is: contrary to the traditional supply chain, the process of planning, managing and controlling the effective physical movement of raw materials, intermediate stocks, final products and related information from the point of consumption to the point of origin for the purpose of rationalizing or restoring its value. ${ }^{[1]}$

The significance of reverse logistics for coal mines is obvious. Firstly, is economic significance. Due to poor production conditions and the rapid transfer of goods in coal production lost a lot, which many of them are recyclable and can be re-used after simple repairs, even without any maintenance. The reuse of waste materials saves significant costs without affecting the production of the enterprise. Secondly, is the meaning of management. The management mode of coal mines is still extensive, while the implementation of reverse logistics requires relatively high management level. Therefore, the implementation of reverse logistics can improve the level of refinement of business management.

In addition, due to the relatively large pollution caused by coal production, the recyclable reverse logistics and rational disposal of non-reusable products can greatly reduce the negative impact of coal mines on the environment. 


\section{The characteristics and shortcomings of coal mine reverse logistics}

1) The characteristics of coal mine reverse logistics.

Coal mine reverse logistics mainly refers to the recovery and maintenance reuse of coal production and security materials. The production of coal does not constitute the final product and the final product does not exist the problem of returns, so the contents of the coal reverse logistics are concentrated in the enterprise that mainly are the reverse logistics supply problems. Reverse logistics in the enterprise relative to the supply chain reverse logistics more easily managed by the enterprise.

(1)The objects of reverse logistics are numerous and the quantity is huge.

The general industry reverse logistics involved in the main objects are the finished products and a limited number of varieties. However, since the final products of coal mine are not composed of any purchased raw materials, which are sorts of purchased materials or equipment entered in reverse logistics. The production of coal mines is complicated and the types of materials required are more than ten million that many of them enter the reverse logistics chain and numerous. This feature has a higher requirement for the coal mine reverse logistics management information system database capacity and retrieval speed.

(2)Reverse logistics is closely integrated with the forward logistics process, but it has limited mutual interference.

Many enterprises have some concerns about the practice of reverse logistics management and even prefer to give some discount to downstream in exchange for zero return on the products that an important reason are concerning about the reverse logistics system will have an impact on the existing positive logistics system. However, due to the large number of backflow logistics, coal mines have established various forms of maintenance departments for a long time, which have less crossover with the forward logistics process and merely exist as a material resource, which is not easy to interfere with the forward logistics. Although the two have a business relationship, for the reverse logistics management information system, whose intimacy of data exchange with the forward logistics inferior to other industries.

(3)The time and space distribution of reverse logistics information are more concentrated and easy to manage information.

In general, reverse logistics objects are finished products, which users widely distributed and the retainment of the products can keep a very long time. It is a major challenge faced by various industries in reverse logistics management that how to carry through the track management of product information in such a wide range of time and space. For coal mine reverse logistics, the space distribution is more concentrated due to the centralized use of products within the enterprise. Coal mine materials are means of production. Due to the requirement of utilization rate, the service life of all materials and equipment is generally shorter than the finished products of other industries, so the time distribution is also more concentrated. The centralized distribution of time and space is conducive to the centralized management of reverse logistics information in coal mine.

(4)The links of reverse logistics are controllable and less uncertainty.

One of the biggest difficulties in the practice of reverse logistics enterprises is that there are too many reverse logistics links and the compositions of enterprises are independent, neither party can control the entire process. It can be said that reverse logistics management must be the supply chain management. The cross-enterprise process management is full of uncertainty, which brings tremendous difficulty to reverse logistics management. However, coal mine reverse logistics is almost concentrated in the enterprise. The entire process can be coordinated by the internal administrative or internal contract of the enterprise and its reliability is much higher than other industries. It is not only the the most important advantage of carrying out the coal mine but also put forward requirements for information integration of reverse logistics management information system in the enterprise.

2)The shortcomings of coal mine reverse logistics.

(1)The management level of reverse logistics supplies is relatively low. ${ }^{[2]}$ 
Modern enterprise management is attaching more importance to logistics management. However, the current management of reverse logistics of material supplement still has a lot of problems and the management level is relatively low that can not meet the requirements of modernization. Mainly assumes that the relevant system construction of reverse logistics is still not completed, mostly used the manual management methods, which led to a big problem in link connection. While without the premise of relevant system as a guarantee, not only a great many link operation lacks of maneuverability and the technology of transmitting and disposing the reverse logistics information is backward but also lacks of impeccable reverse logistics information management system and utilization of network resources is low, which restricting the improvement of reverse logistics management.

(2)Deal with the changing and refunding of procurement supplies in time.

Many coal companies encounter the issues that they are difficult to return the substandard quality materials. At present, only a small part of the coal enterprises set up the special changing and refunding organization. Basically, the changing and refunding operation of the coal enterprise is only the reverse of the original procurement process, which lead to the time period of changing and refunding is generally longer. At the same time, the inconvenience of information exchange also causes many problems when dealing with these problems. Whereas the entire returning operating procedure is pretty cumbersome, which needs to the audit and approval of many different subordinate departments. Generally, when the enterprise requires sales return used coal mine found that the quality does not meet the requirements of the product, reflect to the superior step by step firstly, which means the coal used unit reports to the mine supply department, secondly, the supply department responds in written form to the mine supply station, thirdly, the supply station responds to the business section of the material supply company. Finally, the business section contacts the supplier and waits for the delivery from the supplier. The intermediate process gives rise to unnecessary time waste, even sometimes requires a month before and after from apply for returning to assign the application, affecting the normal production work.

(3)The phenomena of optionally disposing scrapped materials are serious.

Coal companies often have a lot of useless substances and the amount of these materials are generally relatively large. In the past, coal companies basically do not manage such materials, which resulted in a great waste. In many cases, all production units handle their own work, which leads many people to seek benefits from them. In the absence of a unified arrangement and planning, in addition there are no relevant provisions leading to the phenomena of optionally disposing scrapped materials are serious.

(4)A high proportion of backlog of supplies. ${ }^{[3]}$

The entire coal industry exists the supplies backlog problem. For example, one coal mine merely due to the equipment update, the amount value of the obsolete and idle materials and fittings have more than three million yuan, thus it can be seen that the amount of overstocked materials is extraordinary huge in entire coal mine industry, which is too hard to solve once overstocked. Since a lot of materials can no longer flow effectively among the various production units in coal enterprises, there is a certain amount of backlog of materials in various production units and these materials can only basically be consumed by the production units where the materials are located. For example, material management has a certain lag inefficiency, duplication of labor and other phenomena, especially the material management model has obvious lag. At present, the coal enterprises in our country have many unique characteristics that are formed under the special economic and political environment of our country, which mainly assume as generally small scale leading to decentralization of resources comparison. It is common to see the merging among the coal enterprises that the large-scale coal enterprises restructuring the small coal enterprises, making the resources began to concentrate, which requires large-scale coal enterprises need to improve their own material management level by regulating the behavior of resources management and formulating relevant management systems to increase management potency dimension. These are also the key issues that the coal enterprises are paying attention to currently because it is a very 
effective way to enhance competitiveness of the enterprises when the coal enterprises are reorganized.

\section{Application of reverse logistics theory in coal mine}

According to the characteristics of the coal mine reverse logistics, the mine is implemented in the specific reverse logistics management as follows: The recovery mainly depends on the workers working underground. When workers come down from the mine with the underground waste materials together. Workers bring the supplies brought to the waste library and the waste library staff estimated its value according to the material circumstances then issued a receipt for the recovery of waste materials. The worker submits the receipts to finance section to summary, then the finance section will regard these as a subject in the end of the bonus table of the worker.

In order to enhance the enthusiasm of the production sector, coal mines can record the recycle and reprocessed materials by reverse logistics into their production costs at a lower price to encourage the use of recycled materials in various production sites.

After the waste materials enter the waste repository, the waste repository will check them regularly and divide all the waste into three parts: directly-usable products, maintenance-required products and non-utilization waste products. For directly-usable goods, the waste repository directly allocates to the original use department or other directly-usable departments which will be used equally as new materials. For the maintenance-required products, the waste repository allocates to the original use department or other directly-usable departments after maintenance, only when the inventory of the maintenance supplies used up new supplies can be used. It can be sold for unused waste collected that has no use value.

Since most of the supplies in the coal mine reverse logistics are relatively easy to maintain, they can be repaired by the auxiliary work area of the coal mine after classification. The repaired materials can be directly integrated into the coal mine logistics center using by various work areas. For some high value and complex maintenance materials, coal mine groups can implement reverse logistics management uniformly.

\section{Conclusion}

The problem of reverse logistics in coal mines has a long history. With the increasing economic pressure, the urgency of reverse logistics management for coal mines has become increasingly prominent. A complete reverse logistics management information system is one of the keys to reverse logistics management. It is difficult to solve these coal mine reverse logistics problems effectively using traditional information technology. Due to the advantages of IOT technology, the coal mine reverse logistics information management system based on the Internet of Things is bound to be widely used in coal mines in the future. It not only promotes the progress of coal mine reverse logistics management, but also advances the development of coal mine closed loop logistics, which makes closed loop logistics management truly become the profit source and core competitiveness of coal mines.

\section{References}

[1] Rogers D S. and Tibben-Lembke R S. Going backwards: Reverse Logistics Trends and Practices[M]. Nevada Reno: Reverse Logistics Executive Council, 1999,(2).

[2] Liu hui,Wang Jianjun,Gao Zongfei. Reverse Logistics Analysis of Coal Enterprises in Supply Chain [J]. Coal Engineering,2009 ( 5) : 74-76

[3] Song Xiaohong. Research on Reverse Logistics of Material Supply in Coal Enterprises[J]. Chinese coal,2008 (11) : 37-40 